\title{
Une introduction à l'archéologie du royaume du Bosphore Cimmérien
}

\section{Pascal Burgunder}

\section{(2) OpenEdition}

\section{Journals}

Édition électronique

URL : http://journals.openedition.org/edl/298

DOI : $10.4000 /$ edl.298

ISSN : 2296-5084

\section{Éditeur}

Université de Lausanne

\section{Édition imprimée}

Date de publication : 15 mai 2012

Pagination : 17-56

ISBN : 978-2-940331-27-7

ISSN : 0014-2026

\section{Référence électronique}

Pascal Burgunder, "Une introduction à l'archéologie du royaume du Bosphore Cimmérien », Études de lettres [En ligne], 1-2 | 2012, mis en ligne le 15 mai 2015, consulté le 22 décembre 2020. URL : http:// journals.openedition.org/edl/298; DOI : https://doi.org/10.4000/edl.298 


\section{UNE INTRODUCTION À L'ARCHÉOLOGIE DU ROYAUME DU BOSPHORE CIMMÉRIEN*}

L'exploration archéologique des établissements grecs fondés sur le littoral septentrional de la mer Noire, en particulier des cités de l'antique royaume du Bosphore Cimmérien, a suscité quelques récentes publications accessibles à un lectorat non russophone. Cette vitalité éditoriale nous invite à un mouvement rétrospectif visant à présenter des éléments d'histoire de la recherche archéologique de cette région. On découvre ainsi que des Suisses se sont intéressés au patrimoine archéologique de la Russie méridionale dès le XIX ${ }^{\mathrm{e}}$ siècle. On décrit ensuite les développements que connut l'archéologie bosporane durant la période soviétique, par l'exemple de l'épigraphie, puis en parcourant les publications de savants soviétiques destinées au public occidental. Un bref passage en revue des études récentes sur ce propos conclut notre étude.

A Gabriel

La profusion récente d'ouvrages renouvelant nos connaissances de l'histoire antique des rivages de la mer Noire éveille la curiosité et interroge. Reliée à la mer Méditerranée par un détroit, comme un foetus est relié à sa mère par le cordon ombilical, la mer Noire accroît le monde hellénique dès l'époque archaïque. Le bassin de l'antique Pont-Euxin présentait

* Je dois au soutien de la Fondation Gandur pour l'Art d'avoir pu rédiger cette contribution. Mes remerciements s'adressent également à Sophie Bujard, Michel Fuchs et Heinz Heinen qui, à un stade ou à un autre de ce travail, m’ont fait profiter de leurs critiques. Les illustrations ont été gracieusement mises à disposition par les services photographiques du Musée d'ethnographie de la ville de Neuchâtel, par le directeur du Musée des Antiquités de Théodosie, Monsieur Andrej Anatol'evič Evseev, ainsi que par la directrice des Archives de l'Académie des Sciences de Russie à Saint-Pétersbourg, Madame Irina Vladimirovna Tunkina. 
un visage relativement homogène durant l'Antiquité gréco-romaine, avec une langue, un panthéon et un espace commercial communs. Il est aujourd'hui au croisement bigarré de langues et de cultures. Cette diversité actuelle n'est pas étrangère à la perplexité que suscite parfois l'archéologie pontique; elle rend d'autant plus nécessaire l'éclosion d'entreprises éditoriales aux perspectives aussi bien diachroniques que synchroniques ${ }^{1}$.

Les derniers développements de l'archéologie du littoral nord de la mer Noire, du royaume du Bosphore Cimmérien en particulier, désormais accessibles sous forme synthétique à un public non russophone, occasionnent la thématique que nous souhaitons aborder dans le cadre de la présente contribution. Les résultats des investigations de terrain que nous présentent les archéologues russes et ukrainiens sont le fruit de longues années d'effort; ils cristallisent parfois sur quelques pages le labeur ininterrompu de plusieurs générations de chercheurs. En effleurer les strates, méconnues ou ignorées, c'est approcher l'archéologie bosporane au prisme de son histoire et prendre part au processus d'intégration d'un véritable "phénomène ${ }^{2}$ scientifique dans une démarche épistémologique globale.

La découverte des antiquités de Russie méridionale passe par la Suisse! Tout au moins peut-on mettre au crédit de quelques Confédérés, que nous choisissons d'évoquer ici, une fascination sincère pour le patrimoine archéologique que l'Empire russe s'approprie lors de sa conquête des rives septentrionales de la mer Noire. Le coup d'Etat bolchevique met un frein précipité à cet engouement helvétique et coupe pour ainsi dire la Russie et ses archéologues de tout contact régulier avec les chercheurs du camp «bourgeois». Les études épigraphiques, et plus précisément les travaux de publication d'un Corpus des inscriptions bosporanes que nous dépeignons plus bas, illustrent les développements que connut une discipline historique connexe à l'archéologie en contexte soviétique.

I. Le cloisonnement des disciplines scientifiques, y compris au sein des sciences historiques, ajouté aux compartimentages linguistiques et nationaux, rend ce vœu aux allures encyclopédiques bien difficile à exaucer. On peut à ce titre saluer quelques heureuses exceptions dans les ouvrages de M. Koromila, The Greeks and the Black Sea ou encore de Ch. King, The Black Sea.

2. C'est le terme retenu par les organisateurs d'un congrès archéologique qui se tient régulièrement à Saint-Pétersbourg, le "phénomène bosporan". 
A l'articulation chronologique et sémantique de notre cheminement se dresse la synthèse de Viktor F. Gajdukevič traitant du royaume du Bosphore Cimmérien. Ce jalon dans l'histoire de la recherche bosporane paraît également en traduction allemande, ce qui nous incite, dans la perspective adoptée ici, à considérer les investigations et les problématiques archéologiques de la région telles qu'elles sont exposées au public occidental, dans des ouvrages rédigés à son attention par des archéologues soviétiques. On voit ainsi émerger une littérature peu connue, mais pourtant susceptible de servir de matériau à une étude plus poussée des buts, des méthodes et des résultats de l'archéologie soviétique sur ses rivages hellénisés.

Enfin, et pour faire écho aux premiers balbutiements de l'archéologie bosporane, les derniers résultats des investigations de terrain, réunis parfois dans de lourds volumes aux visées moins synthétiques que compilatoires, sont restitués au lecteur non russophone pourvus de quelques commentaires critiques.

\section{Au service du patrimoine archéologique de l'Empire russe}

Les liens qui unissent les cantons suisses à l'Empire de Russie vont s'intensifiant au fil du XIX ${ }^{\mathrm{e}}$ siècle, de pair avec le flux migratoire que l'on sait ${ }^{3}$. Et l'intérêt marqué pour les vestiges antiques qui ponctuent le littoral de la mer Noire, nouvellement conquis sur l'ennemi ottoman, ne faiblit pas: ils exercent une fascination que ne démentiront pas les trois personnages dont nous évoquons ici brièvement le destin. Il s'agit de Suisses romands - un Neuchâtelois, un Genevois et un Fribourgeois qui jouèrent un rôle dans l'étude du patrimoine archéologique des territoires méridionaux de la Russie. S'ils n'ont pas eu l'heur de se fréquenter, les trois Confédérés connurent des débuts identiques dans l'enseignement de la langue française. Précepteurs exerçant dans l'une ou l'autre province de l'Empire - si ce n'est, pour Florian Gille, à Saint-Pétersbourg même -, ils se distinguent tous trois par une curiosité aux facettes multiples s'exprimant dans un intérêt pour les monnaies, les inscriptions et les antiquités de tous ordres.

3. Voir à ce propos l'introduction du présent volume. 


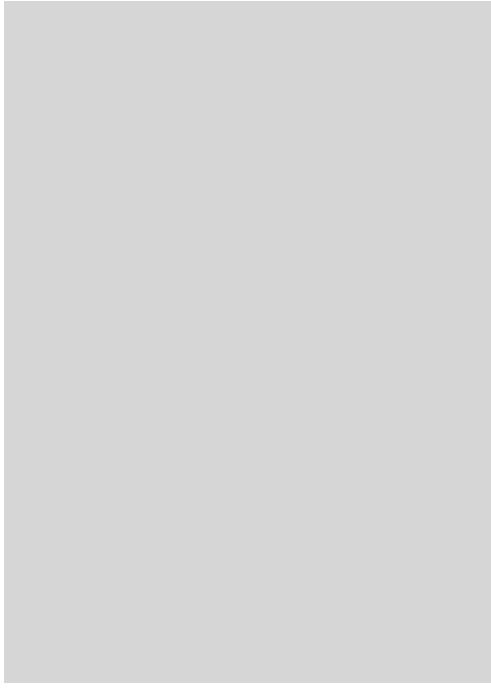

Fig. 1 - Portrait de Frédéric Dubois de Montperreux publié par D. Herter à Zurich en 1850.
Sans doute le plus fameux représentant des cantons suisses à s'être entiché des antiquités de Russie méridionale, Frédéric Dubois de Montperreux (1798-1850) fait figure de pionnier (fig. 1). Son chefd'œuvre, Voyage au Caucase, chez les Tcherkesses et les Abkhases, en Colchide, en Géorgie, en Arménie et en Crimée, sous un titre laissant augurer d'une relation de voyage, est en réalité un ouvrage de portée encyclopédique qui fit date. La leçon inaugurale de celui qui allait devenir professeur à l'Académie de Neuchâtel sert de point de départ à Denis Knoepfler qui produit la biographie la plus complète à ce jour du savant Neuchâtelois ${ }^{4}$.

Car sa terre natale, alors encore possession prussienne, exerça toujours sur lui une indéfectible attraction. Héritier de cette curiosité universelle propre aux savants des Lumières, Dubois de Montperreux jette d'abord son dévolu sur les "vieilles pierres" de la région des Trois-Lacs. Mais sa pauvre patrie ne lui offre guère de quoi vivre et il rejoint bientôt, en 1819 , les provinces baltes de l'Empire russe où il sera employé en qualité de précepteur. D’abord fasciné par la civilisation égyptienne, Dubois porte ensuite son attention sur les rapports entre Grecs et Barbares en Russie méridionale, que sa lecture de Raoul-Rochette avait contribué à éveiller ${ }^{5}$. Il décida à cette date du périple qu'il n'entamera que plus tard, de 1831 à 1835. Dans l'intervalle, il passe quelques années à Berlin où, employé comme précepteur d'un aristocrate polonais, il s'inscrit aux cours d'August Boeckh, le père du Corpus inscriptionum graecarum. Les observations, dessins et autres documents qu'accumule Dubois lors de

4. Voir D. Knoepfler, «Frédéric Dubois de Montperreux» ainsi qu’une contribution préparatoire, antérieure d'une dizaine d'années, du même auteur «"Misit Dubois Neoburgensis" ".

5. Désiré Raoul-Rochette, archéologue français en charge du Cabinet des Médailles à Paris, avait publié en 1822 un ouvrage intitulé "Antiquités grecques du Bosphore Cimmérien». 
son périple forment un gisement considérable d'informations tenant de la géologie, de la géographie, de l'ethnographie et de l'archéologie publiées en six forts volumes à Paris entre 1841 et 1843, grâce à l'aide d'un important subside concédé par le tsar. On retrouve ensuite Frédéric Dubois de Montperreux à Neuchâtel où il est installé en chaire d'archéologie à l'ouverture de l'Académie, en 1841. On reconnaît son esprit avant-gardiste lorsqu'il dénonce, durant ses cours, l'hellénocentrisme excessif dont font preuve les philologues et philosophes de son époque, réfractaires à l'idée d'influences exercées sur la Grèce de l'extérieur. Il mettra du reste la colonisation grecque en mer Noire au programme de ses cours.

La vie et l'œuvre de Florian Gille (1801-1865) n'ont que récemment fait l'objet d'une étude d'ampleur ${ }^{6}$. Natif de Genève où il achèvera des études universitaires, Gille part en négociant à l'assaut de l'Orient. Naples, Constantinople et Odessa seront au nombre des étapes du jeune homme qui aboutit finalement à Saint-Pétersbourg. Il y entamera une brillante carrière de pédagogue, d'abord engagé en qualité de professeur de français par le pasteur zurichois Johannes von Muralt. Recommandé par son protecteur à la cour, Gille devient bientôt le précepteur d'un grand prince de la famille impériale, le futur Alexandre II. Cette position prestigieuse lui octroie bien des avantages et lui assure également une ascension sociale très rapide. En 1840, on confie au Genevois la direction du Premier département de l'Ermitage; il s'astreindra dans les années qui suivront à dresser un inventaire minutieux des collections placées sous sa responsabilité et qui comprennent tant les bibliothèques de la cour impériale que le Cabinet des Médailles ou les Antiquités de Kertch. Déployant ses talents au service du musée, Florian Gille s'entoure d'un personnel qualifié, organise les collections et en publie un premier descriptif fort de quatre cents pages ${ }^{7}$. Il s'est auparavant consacré à la rédaction d'un catalogue systématique des antiquités bosporanes

6. Autrefois responsable de la bibliothèque du Musée d'Etat de l'Ermitage, Germaine Pavlova s'est consacrée à retracer l'histoire de F. Gille et, par là, a réhabilité son lointain prédécesseur. Un premier aperçu de ses recherches est paru en allemand (cf. G. Pavlova, "39 Jahre am Hof zweier Zaren»), tandis qu'une monographie en russe revisite dans le détail le parcours extraordinaire du Genevois (cf. Ž. K. Pavlova, Florian Žil' i Imperatorskij Ėrmitaž).

7. Le volume est paru en 1860 à Saint-Pétersbourg sous le titre de: Musée de l'Ermitage: notice sur la formation de ce musée et description des collections diverses. 


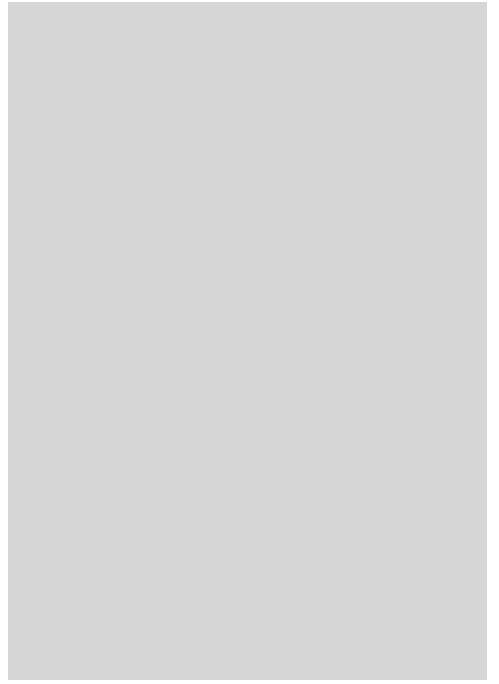

Fig. 2 - Portrait photographique de Louis Kolly.

publié en russe et en français à SaintPétersbourg ${ }^{8}$. L'étoile du conservateur perd cependant de son éclat à la mort de Nicolas I ${ }^{\mathrm{er}}$, intervenue soudainement durant la guerre de Crimée, en 1855. Gille est dessaisi de ses fonctions et décide de quitter la Russie en 1864. Il mettra fin à ses jours sur le chemin du retour en Suisse.

A l'instar de nombre de ses compatriotes, le Fribourgeois Louis Kolly (1849-1918) débute sa trajectoire professionnelle dans l'Empire russe par l'enseignement de la langue française ${ }^{9}$. Sa très succincte autobiographie, rédigée quelques mois avant sa mort, nous apprend qu'il entame sa carrière à Kaunas, en Lithuanie (fig. 2). De nouvelles affectations l'entraînent des provinces baltes à Odessa où il exerce dans diverses institutions privées. Kolly rejoint Théodosie, une ville située dans l'est de la presqu'île de Crimée, en 1879. Il affectionnera suffisamment l'endroit pour y passer le reste de son existence. Sur proposition de la Société impériale d'histoire et des antiquités d'Odessa, le professeur de gymnase reprendra en 1900 la direction du Musée des Antiquités de Théodosie, fondé par un Italien en 1811. Il occupe ce nouveau poste avec bonheur, s'attachant à classer et développer les collections du musée, s'engageant activement en faveur de la sauvegarde du patrimoine historique criméen et innovant avec la mise sur pied, dès 1905, de fouilles sous-marines menées au large de la ville portuaire. Louis Kolly s'illustre avant tout par ses travaux sur la période médiévale, en particulier sur l'installation de colons gênois à Théodosie

8. Les Antiquités du Bosphore Cimmérien conservées au Musée impérial de l'Ermitage comptent deux volumes de texte assortis d'un riche album de planches parus à SaintPétersbourg "par ordre de Sa Majesté l'Empereur».

9. L'essentiel de la documentation disponible - encore fragmentaire - a été récolté et présenté par È. B. Petrova dans divers ouvrages dont le collectif dirigé par E. Žarkov, paru dernièrement (cf. E. I. Žarkov [otv. red.], Sotrudniki feodosijskogo muzeja drevnostej, p. 49-55). 
et leurs relations avec le khanat de Crimée. Des photographies des fortifications gênoises, d'inscriptions datant de cet intermède italien dans l'histoire de Théodosie ainsi qu'un plan de la ville sont exposés à Milan, lors de l'Exposition universelle de 1906.

A parcourir cette galerie de portraits, on perçoit l'apport remarquable de chacun des trois Suisses à l'étude et à la divulgation d'un patrimoine archéologique à la fois si "caractéristique" de l'Europe - la Grèce et Rome ne sont-elles pas aux origines de l'Europe des Lumières, puis des Nations? - et si teinté d'exotisme. Parfaitement dévoués à leur passion de l'antique, ces compatriotes dont l'œuvre est largement méconnue laissent dans le sillage de leur vie des points d'attache qui nous incitent à explorer la discipline archéologique au double prisme des «histoires de vie» et des courants de société qu'elles intègrent.

\section{Champ de l'épigraphie}

Parmi les sciences susceptibles de satisfaire à une telle approche, nous avons choisi l'épigraphie bosporane - chère déjà à Dubois de Montperreux - dont nous esquisserons quelques-uns des développements au fil du XXe siècle. L'élaboration et la publication d'un corpus des inscriptions grecques et latines du Bosphore Cimmérien constituent un épisode de choix dans la vie de ce champ d'études, réputé «auxiliaire» de l'histoire. Les vicissitudes du siècle, le destin des hommes et des femmes qui y furent confrontés, mais aussi la réception même du corpus épigraphique qu'ils constituèrent, à l'intérieur de l'Union soviétique, comme auprès du public occidental ("bourgeois», aurait-on dit), font la matière d'une première partie et sont autant d'éléments qui doivent servir à une mise en perspective historiographique. La deuxième partie présente l'une des figures marquantes de l'épigraphie soviétique, puis russe, de ces dernières années, dans des contributions accessibles à un public non russophone. 


\section{II.1. Le Corpus Inscriptionum Regni Bosporani (CIRB)}

L'édition des inscriptions bosporanes est intimement liée à la personne de Vasilij Vasil'evič Latyšev (1855-1921) (fig. 3) ${ }^{10}$. Le savant russe collecta et traita à lui seul plusieurs centaines de documents épigraphiques qu'il édita en un recueil intitulé Inscriptiones Orae Septentrionalis Ponti Euxeini (IOSPE) paru en trois volumes à Saint-Pétersbourg entre 1885 et $1901^{11}$. Il rassemblait photographies, aquarelles, dessins et estampages d'inscriptions récemment découvertes dans l'espoir de publier une nouvelle édition du tome II quand la mort mit un terme prématuré à son projet. Le dossier est ensuite repris par S. A. Žebeljov, un antiquisant de la génération de M. I. Rostovtsev resté en Russie soviétique, mais ne connut pas une issue plus favorable: le savant mourut en 1941 lors du siège de Leningrad sans avoir pu achever l'édition du deuxième tome des IOSPE consacré aux inscriptions grecques et latines du royaume du Bosphore Cimmérien.

D'autres tentatives se répétèrent dans la période d'après-guerre, mais n'aboutirent pas. La documentation dont héritaient les continuateurs de l'œuvre de Latyšev ne cessait toutefois de croître à mesure que les fouilles archéologiques amenaient leur moisson de nouveaux témoignages épigraphiques. Le principe d'une édition avec traduction et commentaire en russe (en lieu et place du latin) avec une vaste partie réservée aux illustrations semblait désormais acquis. L'équipe de spécialistes dirigée par l'Académicien Vasilij Vasil'evič Struvje (1889-1965) parvint à ses fins après avoir accompli un énorme travail de vérifications dans les collections des musées soviétiques: le recueil des Inscriptiones Regni Bosporani (CIRB) fut publié en 1965.

Io. Dans la vaste fresque qu'il peint des sciences de l'Antiquité en Russie, È. D. Frolov (Russkaja nauka ob antičnosti, p. 233-242) dédie quelques pages à l'œuvre du savant. Pour une relation plus détaillée de la vie et de l'œuvre de Vasilij Vasil'evič Latyšev, on se reportera à l'article du même È. D. Frolov paru en introduction à la réédition des tomes I et II de Očerk grečeskikh drevnostej de V. V. Latyšev, «Kavaler ordena belogo orla».

II. Le premier volume des IOSPE, paru en 1885, traite de Tyra, Olbia, Chersonèse Taurique et d'autres cités de Crimée occidentale; le deuxième volume, paru en 1890, ainsi que le quatrième, paru en 1901 sont entièrement consacrés au royaume du Bosphore Cimmérien et totalisent 733 inscriptions. Le troisième devait être réservé aux inscriptions mineures (dipinti et graffiti); il n'est jamais paru. 


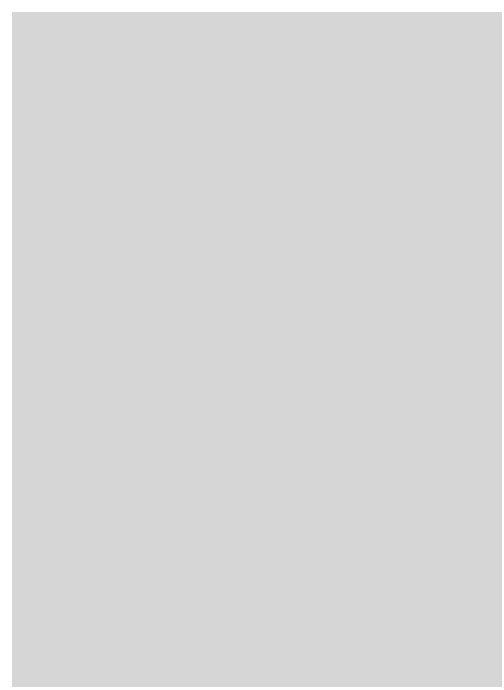

Fig. 3 - Portrait photographique de Vasilij Vasil'evič Latyšev.
Les quelque 1316 inscriptions répertoriées dans le corpus ${ }^{12}$ sont classées selon leur provenance, un principe adopté plus tôt par Latyšev ${ }^{13}$. Elles obéissent ensuite à une sériation répondant aux critères de la typologie: décrets de proxénie, inscriptions votives, inscriptions honorifiques, inscriptions sur bâtiments, manumissions, inscriptions de thiases, listes de noms propres, inscriptions versifiées, inscriptions funéraires suivies de varia. Le corpus des inscriptions bosporanes répertorie des documents datés du $\mathrm{V}^{\mathrm{e}} \mathrm{s}$. av. J.-C. au IVe s. apr. J.-C., le plus récent - l'épitaphe d'un chrétien étant rapporté à l'an 304. La capitale du royaume, Panticapée, fournit l'essentiel des témoignages épigraphiques: 867 notices sont consignées à cet endroit, ce qui équivaut environ aux deux tiers du corpus ${ }^{14}$. Les collections les plus représentatives proviennent ensuite, par ordre d'importance, de Gorgippia, Tanaïs, Hermonassa, Phanagorie, Nymphaion et Myrmèkion. Sur l'ensemble des inscriptions reproduites dans le CIRB, seule une quarantaine est inédite ${ }^{15}$. Le corpus est encore pourvu de

I2. A titre de comparaison, on notera que les tomes II et IV des IOSPE cumulaient 780 inscriptions. A. I. Boltunova ("Neskol'ko slov o "Korpuse Bosporskikh nadpisej" ", p. 231) estime à près de 1200 le total des documents collectés par V. V. Latyšev avant sa mort pour la deuxième édition du tome II des IOSPE. L'apport réel de Struvje et de ses collaborateurs, insinue l'épigraphiste soviétique dans sa recension de 1966, n'est donc pas aussi remarquable que la critique peut le laisser croire.

I3. J. Pecirka, ("Corpus inscriptionum regni Bosporani", p. 295) dénombre avec regret les pertes occasionnées aux collections lapidaires des musées du sud de l'URSS durant la première moitié $\mathrm{du} \mathrm{XX}^{\mathrm{e}}$ siècle; on se heurte régulièrement, regrette-t-il, à la mention «localisation actuelle inconnue».

I4. Dont 650 trouvent place dans la rubrique des inscriptions funéraires.

I5. Ces inédits ont été préparés par A. I. Boltunova qui dut quitter l'équipe rédactionnelle avant la fin des travaux éditoriaux suite à un différend intervenu avec plusieurs de ses membres. On trouve trace de cette dissension dans sa contribution parue en 1966 où elle peine à cacher son amertume de n'avoir pas été citée parmi les contributeurs du 
huit indices, d'un lexique ainsi que d'un essai grammatical traitant des particularités des inscriptions bosporanes.

Cette brève description structurelle du $C I R B$ suffit à en signifier l'ampleur et l'importance pour toute étude se penchant sur l'histoire antique de la région et bien au-delà. L'effort consenti par les savants soviétiques n'a pourtant guère trouvé d'écho dans le monde occidental, la faute en revenant certainement à la décision des éditeurs de publier leur ouvrage en langue russe. Mal diffusé, le CIRB n'a pu profiter qu'au cercle restreint des épigraphistes maîtrisant la langue de Pouchkine. Un aperçu des recensions à lui être consacrées confirme cet état de fait: à l'exception de deux comptes rendus dressés pour l'un par J. Pecirka dans le Journal of Hellenic Studies, pour l'autre par F. Bosi dans la revue italienne Epigraphika ${ }^{16}$, aucune recension détaillée de l'ouvrage n'est parue hors du bloc socialiste ${ }^{17}$. L'essentiel des critiques se concentre sur l'absence complète d'illustrations: au motif d'un financement insuffisant, les éditeurs du CIRB ont dû renoncer à reproduire cartes, photographies ou dessins pourtant soigneusement accumulés durant des années de travaux préparatoires ${ }^{18}$. L'onomastique n'est abordée que ponctuellement et reste au nombre des desiderata de la recherche épigraphique, comme le reconnaît lui-même V. V. Struvje en introduction. Enfin, il faut se reporter à une étude menée par A. I. Boltunova et T. N. Knipovič - appendice indispensable au $C I R B$ - pour prendre connaissance d'observations paléographiques systématisées ${ }^{19}$.

$C I R B$, alors que le souvenir de V. V. Latyšev lui-même, qui est à ses yeux le véritable auteur du corpus, n'est évoqué qu'incidemment (A. I. Boltunova, "Neskol'ko slov o "Korpuse Bosporskikh nadpisej" ").

I6. J. Pecirka, "Corpus inscriptionum regni Bosporani» et F. Bosi, "Note epigrafiche bosporane».

17. Louis Robert mentionne bien le corpus dans le «Bulletin Epigraphique» de 1966 aux $n^{\text {os }} 282$ et 403 en promettant un compte rendu auquel il ne devait manifestement pas pouvoir donner suite. Pour les recensions du bloc socialiste, cf. O. O. Krjuger, «Korpus bosporskikh nadpisej" (en russe), N. V. Pigulevskaja, "Korpus bosporskikh drevnostej" (en russe), B. Nadel, "Le Corpus inscriptionum regni Bosporani et quelques questions de méthode en épigraphie» (en polonais) et I. I. Russu, "Corpus inscriptionum regni bosporani (CIRB)»(en roumain).

I8. O. O. Krjuger, "Korpus bosporskikh nadpisej" s'indigne de ces manquements qui diminuent la portée de l'édition: «on n'édite plus de la sorte!».

I9. Voir A. I. Boltunova, T. N. Knipovič, «Očerk istorii grečeskogo lapidarnogo pis'ma na Bospore». 
Le lecteur francophone curieux des progrès de l'épigraphie soviétique obtenus jusqu'à la fin des années soixante aura par ailleurs pu se familiariser avec les découvertes faites sur le littoral septentrional de la mer Noire - aussi peu accessible durant la guerre froide que le reste du territoire de l'URSS - par le biais d'un article synthétique d'Anna Boltounova publié dans la revue est-allemande $\mathrm{Klio}^{20}$.

Le matériau iconographique patiemment collecté et déposé aux archives de l'Institut d'histoire de la culture matérielle de SaintPétersbourg ne sera enfin exploité qu'au jour où un groupe d'antiquisants placé sous la direction d'Aleksandr Konstantinovič Gavrilov s'attela à reprendre ce volumineux dossier pour en tirer un «album " publié en $2004^{21}$.

On doit à Sergej Remirovič Tokhtas'ev l'essentiel des avancées récentes produites dans le champ de l'onomastique bosporane. L'épigraphiste pétersbourgeois a ainsi traité de la problématique des patronymes réputés de provenance thrace ${ }^{22}$; il poursuit en outre une chronique onomastique au sein de la revue Hyperboreus, publiée par la "Bibliotheca Classica» de Saint-Pétersbourg.

\section{II.2. L'œuvre de Jurij Germanovič Vinogradov}

On peut sans conteste parler de Jurij Germanovič Vinogradov (19462000) comme de l'une des figures marquantes de l'épigraphie russe contemporaine $^{23}$. Très tôt actif sur les chantiers archéologiques d'Olbia, puis de l'île de Bérézan, Vinogradov acquiert érudition et sensibilité aux inscriptions provenant des cités antiques du littoral septentrional de la mer Noire. Il publie en 1981 une monographie traitant de l'histoire

20. La contribution de l'épigraphiste soviétique est hélas émaillée d'erreurs de traduction, cf. A. Boltounova, «L'épigraphique (sic) en URSS».

2I. La publication de ce volume de planches, pourtant accueillie favorablement, a été suivie d'un échange de politesses entre S. R. Tokhtas'ev et l'éditeur du volume au travers des pages de Vestnik Drevnej Istorii ainsi que par l'entremise de Bryn Mawr Classical Review.

22. S. R. Tokhtas'ev montre de manière convaincante ( Iz onomastiki Severnogo Pričernomor' ja I» et «Iz onomastiki Severnogo Pričernomor' ja. II. Frakijskie imena na Bospore») combien les occurrences attestées de noms propres thraces sont insignifiantes dans le Bosphore Cimmérien jusqu'à son intégration au royaume de Mithridate VI Eupator, au I ${ }^{\text {er }}$ siècle av. J.-C.

23. Voir la nécrologie du savant dans Vestnik Drevnej Istorii 1 (2001), p. 98-110. 
politique d'Olbia, en langue allemande ${ }^{24}$. Le savant noue des liens solides avec ses collègues occidentaux, en particulier allemands, et le Deutsches Archäologisches Institut dont il devient membre correspondant. En charge d'une chronique auprès du "Bulletin Epigraphique", Vinogradov s'acquitte avec enthousiasme de sa nouvelle tâche en publiant plus d'une centaine de notices dans la livraison de 1990 de la Revue des Etudes Grecques. Il considère alors principalement des publications soviétiques, mais également étrangères, parues de 1978 à 1987 et traitant de documents épigraphiques issus des cités septentrionales de la mer Noire, du Caucase ainsi que de l'Asie centrale ${ }^{25}$. Le savant s'était auparavant livré à un exercice semblable pour le compte d'une revue slovène d'archéologie, en couvrant toutefois une période beaucoup plus longue, allant de la parution des IOSPE de V. V. Latyšev à $1978^{26}$. La livraison de 1996 reflète malheureusement les difficultés croissantes qui allèrent cruellement éprouver les institutions académiques russes à la chute de l'URSS: Vinogradov ne remet alors qu'une vingtaine de notices publiées sous la rubrique «Pont Nord» du «Bulletin» ${ }^{27}$.

La parution à Mayence d'un choix de ses articles les plus significatifs, sous la forme d'un fort volume intitulé «Pontische Studien», consacrait l'œuvre du savant en même temps qu'elle révélait aux spécialistes occidentaux des pans entiers de l'histoire des cités septentrionales du Pont-Euxin ${ }^{28}$. Les contributions rassemblées font la part belle aux documents épigraphiques mis au jour lors des fouilles archéologiques menées à Olbia; le royaume du Bosphore Cimmérien, comme Chersonèse Taurique ou encore le Caucase, occupe le second rang ${ }^{29}$. Placé dans le chapitre introductif de l'ouvrage, un essai exprime plus particulièrement

24. Ju. G. Vinogradov, Olbia.

25. Ju. G. Vinogradov, "Bulletin Epigraphique: Côte septentrionale du Pont, Caucase, Asie centrale».

26. Ju. G. Vinogradov, «Epigraphik in der UdSSR».

27. Ju. G. Vinogradov, «Bulletin Epigraphique: Pont Nord».

28. Ju. G. Vinogradov, Pontische Studien.

29. La section consacrée aux inscriptions bosporanes regroupe quatre articles parus entre 1974 et 1997. Le premier article évoque un graffito datable du VI ${ }^{\mathrm{e}}$ s. av. J.-C., le deuxième aborde les relations du royaume du Bosphore Cimmérien avec Olbia au IVe $s$. av. J.-C. Le troisième traite d'une inscription votive de la fille du roi scythe Skilouros découverte à Panticapée et datée du $\mathrm{II}^{\mathrm{e}}$ s. av. J.-C.; le dernier article se penche sur le règne de Polémon dans ses rapports avec Chersonèse et la Rome du I ${ }^{\text {er }}$ siècle de l'ère chrétienne. 
le point de vue méthodologique de l'épigraphiste ${ }^{30}: \mathrm{Ju}$. G. Vinogradov souligne l'importance capitale des documents épigraphiques (inscriptions, graffiti ou timbres amphoriques) pour l'histoire des Etats grecs du Pont septentrional et les spécificités de ce genre de témoignages qui trahissent les particularismes d'une culture évoluant au contact des barbares de la steppe. Aussi faut-il dénoncer toute tendance qui réduirait l'épigraphie à un «jeu d'esprit» et l'intégrer, recommande-t-il, au concert des autres sciences de l'Antiquité pour obtenir l'instantané le plus fidèle possible d'un objet précis à une époque donnée ${ }^{31}$. Un autre écrit aborde quelques problèmes méthodologiques par le biais des inscriptions découvertes à Olbia et démontre l'utilité d'un examen méticuleux des supports originaux en vue d'une éventuelle restitution du texte ${ }^{32}$.

Emporté par des hypothèses parfois audacieuses, Jurij Vinogradov propose des restitutions historiques, certes érudites et stimulantes, mais risquées. En soulignant les mérites indiscutables du savant russe, la critique occidentale ne cache pas une propension à vouloir arrimer à la "grande histoire" des documents épigraphiques plus modestes ${ }^{33}$. En Russie, les thèses avancées par Ju. G. Vinogradov connaîtront un détracteur acharné en la personne de l'épigraphiste moscovite Valerij Petrovič Jajlenko ${ }^{34}$.

La chronique épigraphique du Pont paraissant dans la Revue des Etudes Grecques revient ensuite tantôt à L. Dubois, tantôt à Ph. Gauthier, avant

30. Ju. G. Vinogradov, "Griechische Epigraphik und Geschichte des nördlichen Pontosgebietes", in Pontischen Studien, p. 74-99.

3I. Ju. G. Vinogradov se fait volontiers l'apôtre d'un traitement "horizontal» du matériau épigraphique qu'il éclaire avec art à la lumière de données provenant des textes, de la numismatique, de l'archéologie, etc.

32. Ju. G. Vinogradov, "Zur Bearbeitungsmethodik griechischer epigraphischer Denkmäler", in Pontischen Studien, p. 355-376.

33. Voir les recensions de Pontische Studien, l'une signée par Ph. Gauthier, "A propos de l'ouvrage de Jurij G. Vinogradov, Pontische Studien", l'autre par J. G. F. Hind, "J. G. Vinogradov, Pontische Studien", ou, pour le cas particulier du bateau Isis, un article de l'auteur écrit en collaboration avec C. Semenzato, «Retour à Alexandrie?».

34. On doit hélas reconnaître un esprit vétillard à la plupart des remarques formulées par V. P. Jajlenko à l'encontre des contributions de son compatriote ( Ju. G. Vinogradov. Pontische Studien. Kleine Schriften zur Geschichte und Epigraphik des Schwarzmeerraumes" puis, dans sa version allemande, "Ueber den Umgang mit pontischen Inschriften»). 
de passer, à la livraison 119 de 2006, à Alexandru Avram, professeur à l'Université du Maine.

\section{Archéologie des cités du royaume du Bosphore Cimmérien}

L'exploration archéologique des rives septentrionales de la mer Noire a débuté peu de temps après que les troupes de Catherine II se soient emparées de ces territoires méridionaux, conquis à la fin du XVIII ${ }^{\mathrm{e}}$ siècle sur l'Empire ottoman. Les officiers russes en poste dans la nouvelle province de Tauride, dont le découpage géographique comprenait la Crimée et la région de Melitopol', succombaient volontiers à la mode des antiquités et en offraient les pièces les plus brillantes à la Cour impériale. C'est ainsi que nombre de kourganes furent éventrés et que les vestiges des cités grecques antiques connurent leurs premiers explorateurs modernes.

L'institution d'une commission archéologique impériale, présidée dès sa création, en 1859, par le comte Sergej Grigor'evič Stroganov (17941882), lui-même collectionneur averti d'antiquités gréco-romaines, promut les investigations archéologiques entreprises sur le territoire russe à un sort plus favorable: le patrimoine archéologique passait sous la protection de l'Etat, il était documenté et conservé dans des musées ${ }^{35}$. Cette évolution correspondait non seulement à une prise de conscience centralisatrice de l'Etat visant à préserver les vestiges de son passé, elle obéissait également à des préoccupations scientifiques émanant des cercles académiques de la capitale. L'étude des antiquités de la mer Noire, cessant d'être l'apanage des seuls conservateurs de l'Ermitage, devient un sujet d'étude bientôt intégré au champ d'activités des historiens russes.

Les sciences historiques connurent un essor spectaculaire en Russie durant le $\mathrm{XIX}^{\mathrm{e}}$ siècle. Sans vouloir entrer dans le détail, il convient de mentionner en particulier, dans le domaine de l'Antiquité classique, le professorat de Fjodor Fjodorovič Sokolov (1841-1909) qui suscita une véritable école d'archéologues et d'historiens de l'Antiquité à l'Université de Saint-Pétersbourg. La pléiade de savants formés dans les universités russes et l'effervescence que connut l'étude des cultures antiques de

35. Organe officiel de l'Etat, la Commission archéologique impériale chapeautait les activités des musées des Antiquités créés plus tôt, à Théodosie en 1811, à Kertch en 1826. 
Russie méridionale - grecque et barbare - durant les dernières années du tsarisme firent la matière d'un chapitre de l'œuvre de Vladislav Petrovič Buzeskul (1858-1931), L'histoire universelle et ses représentants en Russie au $X I X^{e}$ et au début du XX $X^{e}$ siècle.

Il est significatif, nous semble-t-il, que l'ouvrage de Buzeskul ne soit paru qu'à la fin des années vingt, à la rupture de deux époques, mais aussi à un moment où les membres de l'Académie russe avaient depuis longtemps prouvé leur capacité et démontré leur originalité. Il est significatif également que ce livre ait fait l'objet récemment d'une réédition libre des interventions de la censure, en hommage, sans doute, à cette génération d'intellectuels qui fut brimée et partiellement anéantie lors de la guerre civile, puis des purges staliniennes ${ }^{36}$. Ce choix éditorial, outre qu'il participe d'un mouvement plus large de réappropriation - intellectuelle et morale - de tout un pan de l'histoire russe, réhabilite nombre d'érudits et leurs œuvres et rétablit ainsi un lien épistémologique malmené voire renié par la dictature communiste.

Nous reprenons à notre compte ce travail de mémoire en choisissant de présenter, plus proche de nous, la dernière synthèse en date traitant de l'histoire et de l'archéologie du Bosphore Cimmérien. Cet ouvrage de référence, accessible au public occidental dans sa traduction allemande de 1971, Das Bosporanische Reich, est l'œuvre de l'archéologue soviétique Viktor Francevič Gajdukevič (1904-1966). Nous nous bornerons à en montrer ici les articulations et la réception, manifestement réduite hors des frontières soviétiques. Les ouvrages sur le même thème parus du temps de l'Union soviétique à destination d'un public occidental retiendront ensuite notre attention. Le rapport qu'ils font des avancées archéologiques opérées sur les rivages méridionaux de l'Union soviétique nous éclaire non seulement sur la matière des investigations et ses modes d'intervention, mais il nous renseigne également sur les buts poursuivis par les archéologues soviétiques et les thématiques qu'ils développèrent.

Seules chroniques régulières des fouilles soviétiques en mer Noire à paraître en Occident, les Archaeological Reports britanniques maintiennent un lien officiel, certes ténu mais existant, avec les archéologues des cités grecques de l'URSS, dès les années soixante et tous les dix ans. Elles

36. Réédition que l'on doit à Irina Tunkina: V. P. Buzeskul, Vseobščaja istorija i ee predstaviteli v Rossii v XIX $i$ načale XX veka. La septième section (p. 263-297) est réservée à l'étude des antiquités du littoral septentrional de la mer Noire. 
dévoilent bien sûr les principales avancées de terrain, mais se font également l'écho des voies empruntées par la recherche archéologique soviétique. Enfin, la section finale de cette étude fait état des publications récentes présentant les cités grecques du bassin de la mer Noire et de son littoral septentrional en particulier. Sans prétendre à l'exhaustivité, elle recense des œuvres que nous croyons néanmoins représentatives d'une intensification des liens entre les chercheurs occidentaux et ceux issus de l'ancienne URSS.

\section{III.1. Un archéologue de l'Union soviétique: Viktor Francevič Gajdukevič}

L’œuvre et la vie du célèbre archéologue soviétique, né en 1904 dans une famille d'origine polonaise, revêtent une importance particulière pour l'histoire de l'archéologie du royaume du Bosphore Cimmérien au $\mathrm{XX}^{\mathrm{e}}$ siècle. Viktor Gajdukevič a en effet multiplié les investigations de terrain dans la région de Kertch notamment, sans négliger pour autant les travaux de publication qui en découlent ${ }^{37}$. Labsence à ce jour de biographie scientifique - dont s'étonne Ju. A. Vinogradov dans le portrait qu'il dresse de son devancier ${ }^{38}$-, ne doit pourtant pas éveiller de soupçon quant à la qualité de son ouvrage principal, Le royaume du Bosphore, qui reste un travail de référence en Russie et auquel nous reviendrons plus longuement ci-dessous. Appartenant à la première génération d'archéologues soviétiques, Gajdukevič échappe aux tourments du stalinisme et est fait docteur de l'Université de Leningrad en 1938. Il y enseignera de longues années l'archéologie classique. Epargné par les affres de la guerre qu'il vit en évacuation en Asie centrale, l'archéologue retrouve ses fouilles de Crimée orientale qu'il dirige dès l'été de l'année 1946. C’est sur un chantier archéologique qu'il meurt, vingt ans plus tard.

L'ouvrage de V. F. Gajdukevič paru à Berlin en 1971 dans une traduction allemande, Das Boporanische Reich, reprend la version russe de 1949 en l'amplifiant et en y apportant des modifications que nous nous gardons d'analyser ici. Les treize chapitres de la monographie traitant pour la première fois de l'histoire du royaume du Bosphore Cimmérien

37. On lira, infra, les quelques lignes d'Igor Tikhonov à propos de l'archéologue; voir également la figure $11 \mathrm{de}$ son article.

38. Ju. A. Vinogradov, «Pamjati V. F. Gajdukeviča». 
reflètent de manière caractéristique les principaux axes de la recherche archéologique en Union soviétique. La monographie s'ouvre sur un chapitre consacré à la problématique de la colonisation grecque, un sujet sur lequel s'est constamment exercée l'idéologie soviétique. Le chapitre, sensible également, de la fondation de «l'Etat bosporan" se réclame principalement des hypothèses émises par le maître de Gajdukevič, le célèbre Sergej Žebeljov (1867-1941). On retrouve exprimée au chapitre 9 cette fidélité au maitre lorsqu'il est question de "la révolte de Saumakos»: un membre de l'entourage du roi du Bosphore se serait révolté contre son souverain dans un élan de libération des esclaves et du petit peuple. La fabrication de cet épisode, intervenant dans un contexte politique difficile, constitue un cas exemplaire de manipulation des données historiques destinée à flatter le modèle idéologique proclamé par Staline ${ }^{39}$.

Les chapitres 6 et 7 consacrés respectivement à la production agricole, artisanale et artistique du royaume bosporan antérieure à son absorption par le souverain du Pont, Mithridate VI Eupator, et aux villes du Bosphore Cimmérien, forment le cœur de l'ouvrage du savant soviétique. Ils réalisent la synthèse de longues années d'investigations archéologiques et témoignent des efforts colossaux consentis par Gajdukevič sur le terrain, à tenter d'appréhender le fonctionnement économique de cet Etat antique ainsi que les modes de production utilisés alors. Si elles s'inscrivent dans l'air du temps ou semblent répondre à quelque consigne partisane, les recherches entreprises dans le but de mettre au jour le patrimoine matériel des "classes laborieuses» innovent précisément par l'intérêt porté aux traces visibles dans le sol des activités de la vie quotidienne, réputées d'ordinaire négligées par l'archéologie occidentale qualifiée de "bourgeoise» dans la dialectique marxiste-léniniste de l'URSS. Le passage en revue des différentes villes du royaume, dont les notices réservées aux "petites cités", fait la preuve de l'érudition du savant soviétique: il condense sur quelques pages plus de trente années de fouilles archéologiques menées à la tête de «la mission du Bosphore» sur les sites de Myrmèkion, Tiritaka ou Ilouraton - pour n'en citer que quelques-uns ${ }^{40}$. Les deux premiers siècles de l'ère chrétienne sont traités aux chapitres 10 et 11 : le royaume devient vassal de Rome avant de subir

39. Voir à ce propos Z. W. Rubinsohn, «Saumakos».

40. La bibliographie de Viktor F. Gajdukevič ne manquera pas d'éclairer le lecteur sur le vaste champ d'intérêt du savant. 
les assauts, dès la seconde moitié du $\mathrm{III}^{\mathrm{e}}$ siècle, des Goths, des Huns et des Alains.

La préface rédigée spécialement pour l'édition allemande souligne les spécificités du royaume du Bosphore telles qu'elles sont perçues à l'aune d'une idéologie marquée par le stalinisme, qui impose à la recherche historique ses principaux angles d'attaque thématiques. A ce titre, le marxisme-léninisme est censé fournir de nouveaux outils à l'approche méthodologique de l'Antiquité classique qualifiée, dans la catégorisation de J. Engels, de "société esclavagiste» ${ }^{41}$. Viktor Gajdukevič caractérise l'Etat bosporan selon trois critères: géographique, économique et politique. A cheval sur l'Europe et l'Asie, le royaume du Bosphore Cimmérien constitue une zone de contact où ont lieu les échanges entre colons grecs et populations locales, sédentaires et nomades. Cette promiscuité géographique entraîne, au terme de l'approche adoptée, deux corollaires indissociables, l'un économique et l'autre culturel. Tous deux sont cependant marqués au front du sceau du "progrès». D’une part, les rapports économiques qui s'établissent entre les Grecs et les Barbares mènent à la domination d'un groupe par un autre, de même au sein du barbaricum. Cette évolution favorise le passage de l'Urgesellschaft à la Klassengesellschaft. Le glissement au domaine culturel, d'autre part, paraît logique, mais est traité de manière tendancieuse. Ce mouvement est toutefois limité dans son aspect unilatéral: s'il y a bien "intégration» des Barbares (Sindes, Méotes, Scythes ou Sarmates) à l'Etat grec, l'apport original des populations locales est indéniable. Gajdukevič va même jusqu'à faire des dynasties sarmates des premiers siècles de l'ère chrétienne les garantes de la conservation de l'hellénisme dans cette région du monde. Le raisonnement enchaîne logiquement avec une conséquence d'ordre politique: les processus d'intégration des Barbares, la forme politique même de l'Etat bosporan, précurseur des royaumes hellénistiques, font du royaume du Bosphore Cimmérien un phénomène tout à fait original. Une crise de la production conjuguée aux incursions de peuplades de Goths conduit à la fin de ce paradigme et ouvre sur la prochaine étape, le féodalisme.

4I. "Die Untersuchungen gewannen in wissenschaftlich-methodologischer Hinsicht an Wert, weil sie jetzt auf der Grundlage der marxistisch-leninistischen Theorie von den Gesetzen der historischen Entwicklung durchgeführt wurden.»(V. F. Gajdukevič, Das Bosporanische Reich, p. 13). 
On note donc une soumission de la recherche archéologique à la dialectique autoritaire en vigueur en Union soviétique. C'est là un des reproches que Benjamin Nadel adresse à l'édition allemande de l'ouvrage de Gajdukevič, celui d'être "encore influencé par la perspective sociologique des années trente" sur quelques points importants ${ }^{42}$. Depuis lors, la faillite de l'idéologie communiste portera certainement la critique à plus d'indulgence. Juger de la réception réservée à l'ouvrage de Gajdukevič en Occident reste cependant un exercice frustrant. Et pour cause: la seule recension détaillée de l'ouvrage que nous croyons posséder est due à la plume de Benjamin $\mathrm{Nadel}^{43}$. Pour être d'une dizaine d'années seulement le cadet de V. F. Gajdukevič, Nadel connaît parfaitement les circonstances qui entourèrent la parution de la monographie. En louant l'immense effort de synthèse consenti par son confrère, il relève également combien nombreux furent les savants qui, dans le sillage tant de la guerre civile que de la Seconde Guerre mondiale, laissèrent de manuscrits orphelins. A ses yeux, l’ouvrage de Gajdukevič, bien que péchant sur de nombreux points, dont certaines omissions dans le domaine historiographique et des manques dans l'analyse des sources (en particulier épigraphiques et littéraires), complète sans les remplacer totalement les ouvrages antérieurs d'Ellis Minns et de Mikhail Rostovtsev ${ }^{44}$.

\section{III.2. Recherches archéologiques menées en Crimée et à Taman}

a) Ouvrages traitant de l'archéologie bosporane à l'époque soviétique

Le bref parcours bibliographique que nous effectuons ici nous semble revêtir une double importance. Il vise en premier lieu à faire émerger une littérature archéologique souvent ignorée du public éclairé, auquel il s'adresse pourtant. Les Etats grecs du littoral septentrional de la mer

42. La recension de l'ouvrage de Gajdukevič rédigée par Benjamin Nadel pour Gnomon "V. F. Gaidukevic: Das Bosporanische Reich» (en anglais) est paru en traduction française dans la Revue historique de droit français et étranger «Le royaume du Bosphore, un millénaire de civilisation grecque en pays scythe». Nadel quitte l'Union soviétique en 1957 pour la Pologne. Il poursuivra ensuite sa carrière aux Etats-Unis.

43. Une autre critique, très brève, est rédigée par l'historien est-allemand Heinz Schulz-Falkenthal, «V. F. Gajdukevič, Das Bosporanische Reich».

44. E. H. Minns, Scythians and Greeks et M. Rostowzew, Skythien und der Bosphorus. 
Noire y sont abordés dans le détail qu'autorisent les derniers résultats des fouilles. Il se dégage de ce matériau un vaste potentiel historiographique dont on pourrait, ultérieurement, désigner les traits spécifiques à la dialectique soviétique ou, au contraire, dégager les composantes pérennes héritées de l'époque tsariste. Nous présentons donc un choix de trois ouvrages parus à l'époque soviétique et destinés au public occidental en nous gardant cependant de problématiser un aspect plutôt qu'un autre de la recherche archéologique, nous limitant à en désigner les principaux axes.

A. L. Mongait, Archaeology in the USSR, Londres, 1961.

Version révisée d'un essai paru en russe en $1955^{45}$, l'ouvrage de l'archéologue et médiéviste soviétique Aleksandr L'vovič Mongajt (19151974) offre un aperçu des avancées de l'archéologie en Union soviétique durant l'immédiat après-guerre. La traduction anglaise de cette édition destinée au grand public est composée des dix parties que comprend l'original, mais est écourtée "des passages à caractère politique ou idéologique ${ }^{46}$. Un chapitre est consacré tout entier aux cités septentrionales de la mer Noire, ce qui représente une trentaine de pages dont la moitié revient au royaume du Bosphore Cimmérien. Sans rechigner à citer les précurseurs "prérévolutionnaires", A. L. Mongajt fait au contraire des résultats scientifiques obtenus précédemment les prémices de l'archéologie soviétique. L'intérêt des archéologues pour les «petites villes» du Bosphore Cimmérien - Myrmèkion, Tiritaka, Kytée ou Ilouraton - doit en revanche illustrer des préoccupations nouvelles, proprement soviétiques, pour les spécificités socio-économiques d'établissements antiques à population éventuellement mixte. L'archéologie soviétique prête une attention particulière aux conditions de vie de la société antique et des travailleurs ${ }^{47}$ («working masses» dans la traduction anglaise), à la production ${ }^{48}$, ainsi

45. L'ouvrage est traduit en français et paraît à Moscou en 1959 aux «Editions en langues étrangères".

46. Dans un "Translator's Foreword» assez long, l'auteur de la traduction justifie les coupures opérées au motif d'une rhétorique empreinte de l'idéologie stalinienne.

47. La mise en évidence et l'étude du parcellaire de la chôra méridionale de Chersonèse représentent "une des grandes réalisations» de l'archéologie soviétique.

48. La production céréalière - ainsi que celle du vin et du garum - est particulièrement mise en exergue par les archéologues soviétiques. 
qu'à l'évolution socio-économique des populations "autochtones" au contact des colons grecs ${ }^{49}$.

A l'exception notable de l'Anglais E. H. Minns, explique Mongajt en ouverture de propos, peu de savants occidentaux se sont frottés à l'archéologie russe puis soviétique. De ce fait, le patrimoine antique de l'Union soviétique est peu connu à l'étranger - la barrière de la langue aussi bien que les a priori idéologiques tiennent les antiquisants occidentaux éloignés des problématiques et des résultats obtenus par leurs collègues soviétiques ${ }^{50}$. L'archéologie soviétique s'émancipe, en fondant sa propre école, des méthodes et des enjeux de son homologue "bourgeoise»: elle s'impose un renouvellement des problématiques, orientées par les objectifs révolutionnaires et articulées selon les termes de la dialectique marxiste-léniniste ${ }^{51}$.

H. Heinen (dir.), Die Geschichte des Altertums im Spiegel der sowjetischen Forschung, Darmstadt, 1980.

La publication d'un recueil d'articles de spécialistes soviétiques placé sous la direction de Heinz Heinen intervient à une période charnière dans l'histoire de la recherche archéologique soviétique. L'ère de la stagnation brejnévienne touche à sa fin et l'archéologie de l'URSS connaît des développements importants. L'antagonisme idéologique demeure cependant exacerbé entre les deux camps des pays "capitalistes» et "socialistes", ce qui oblige Heinen à présenter la série d'études qu'il introduit de manière très argumentée ${ }^{52}$. La rédaction du chapitre traitant des cités antiques de

49. On cherche ainsi à définir les emprunts des Grecs aux populations locales et inversement ou les interactions entre eux deux.

50. A. L. Mongajt condamne les distorsions qu'engendrent les présupposés politiques de ses collègues occidentaux à l'égard de l'archéologie soviétique et de ses résultats; il regrette également que les publications soviétiques fassent peu souvent l'objet de traductions. Heinen parlera plus tard de «selbstgewählte Isolierung» - les accusations sont prononcées d'un côté et de l'autre du Rideau de fer.

5I. La notion de "matérialisme» imprègne l'idéologie soviétique et tend à favoriser l'étude de la "culture matérielle» des populations anciennes ayant laissé des traces archéologiques sur le territoire de l'URSS.

52. Cet intérêt pour le développement des sciences historiques en URSS se base sur une approche proprement interprétative et non idéologique des études en histoire ancienne, comprises dans le contexte du marxisme-léninisme. La valeur des problématiques et des analyses réalisées par les archéologues et les historiens soviétiques doit 
mer Noire septentrionale constitue une remarquable synthèse revenant à la plume de D. B. Šelov ${ }^{53}$. Amplement annotée mais relativement peu illustrée, la contribution de Šelov ne se limite pas à rapporter les principaux acquis de l'archéologie de terrain sur des sites aussi emblématiques qu'Olbia, Chersonèse ou Panticapée ${ }^{54}$; elle expose d'emblée les principales problématiques abordées, ainsi que les récents développements des sciences "auxiliaires" à l'archéologie. Travaux de synthèse en numismatique, corpus des inscriptions du Bosphore Cimmérien ou encore études portant sur la sculpture, la peinture murale, la toreutique ou les statuettes en terre cuite démontrent la vitalité des sciences de l'Antiquité en URSS. Des moyens techniques nouveaux sont mis au service de l'archéologie: photographie aérienne, archéologie sous-marine ou analyses physico-chimiques sont régulièrement employées au sein de missions archéologiques très nombreuses et actives sur tout le territoire soviétique. En sus des problématiques traditionnelles traitées par l'archéologie soviétique - l'esclavagisme ou les développements socio-économiques des sociétés antiques -, de nouveaux champs d'investigations scientifiques se font jour qui portent, par exemple, sur les particularismes du régime politique bosporan ou encore sur l'intégration des Etats grecs du bassin de la mer Noire au monde hellénique méditerranéen et pontique.

V. Yanine (dir.), Fouilles et recherches archéologiques en URSS, Moscou, 1985.

Destiné à renseigner le grand public francophone du dernier état de la recherche archéologique en URSS, l'ouvrage dirigé par V. Yanine ne trahit pas les attentes de ses lecteurs ${ }^{55}$. Les chapitres qui le composent

ainsi être estimée au prisme d'un système, d'une grille de lecture induite par la dialectique marxiste, toute confrontation avec les travaux occidentaux devenant vaine voire contreproductive.

53. In H. Heinen (dir.), Die Geschichte des Altertums im Spiegel der sowjetischen Forschung, p. 341-402.

54. L'exposé des principaux résultats obtenus par l'archéologie de terrain occupe la part du lion: les pages 348 à 389 passent en revue les nombreuses fouilles entreprises sur les sites des littoraux ukrainiens et russes de l'URSS.

55. A l'instar d'A. L. Mongajt, V. Yanine est un archéologue spécialiste de la Russie médiévale. Dans son introduction au volume, il dresse en quelques pages un tableau de l'archéologie soviétique touchant tant à son organisation, aux publications récentes qu’aux lois qui en régissent les activités. 
sont l'œuvre de spécialistes reconnus : c'est à Dmitrij Chélov qu'il échoit de rédiger la section consacrée aux cités antiques de la mer Noire ${ }^{56}$. Longue d'une trentaine de pages et assortie de photographies de bonne qualité, la contribution de l'archéologue reflète de manière précise autant les avancées récentes de l'archéologie soviétique que les problématiques en vogue à l'heure où débute la Perestroïka. La thématique de la colonisation grecque en mer Noire septentrionale est ainsi abordée sous un angle nouveau, la mixité culturelle de la région d'Olbia comme des établissements ruraux du Bosphore Cimmérien est envisagée à la lumière de nouveaux éléments, tandis que la dynamique des commerces d'importation et d'exportation reste au cœur de l'attention des chercheurs. Le royaume du Bosphore Cimmérien passe pour être un véritable laboratoire du syncrétisme culturel qui s'opère, dans le cadre d'un Etat, entre Hellènes et Barbares ${ }^{57}$. Les résultats des fouilles des "petites villes" situées près de Panticapée conduisent les archéologues soviétiques à en faire autant de petites «banlieues industrielles» de la capitale du royaume. L'intérêt porté aux agglomérations rurales permet de mieux appréhender certains aspects techniques de l'activité agricole, de déterminer la composition ethnique et sociale de la population composant la chôra.

\section{b) Archaeological Reports}

La série des Archaeological Reports publiée conjointement par la Society of the Promotion of Hellenic Studies et la British School at Athens fait régulièrement état des avancées archéologiques opérées sur les sites du bassin de la mer Noire. Les établissements grecs du royaume du Bosphore Cimmérien y sont brièvement présentés et intègrent la koinè pontique - qui comprend les fondations riveraines de la mer Noire situées sur les territoires de Roumanie, Bulgarie, Turquie, Géorgie, Fédération de Russie, Ukraine et Moldavie. On doit le premier rapport du genre à John Boardman ${ }^{58}$ qui, peut-être à la faveur de la "déstalinisation" initiée à l'occasion du XXe Congrès du Parti communiste d'URSS, reprend en 1963 le flambeau des chroniques archéologiques de Russie méridionale

56. D. Chélov, «Les cités antiques de la mer Noire», in V. Yanine (dir.), Fouilles et recherches archéologiques en URSS, Moscou, 1985, chap. III, p. 98-123.

57. Les sites de Nymphaion ou de Tanaïs en fournissent l'illustration éclatante.

58. J. Boardman, "Greek Archaeology Investigations of the Shores of the Black Sea». 
allumé plus tôt par son compatriote Ellis Minns ${ }^{59}$. J. Boardman brosse le portrait des investigations de terrain menées sur les sites antiques du sud de l'URSS depuis la fin de la Seconde Guerre mondiale, en regrettant le fossé linguistique qui sépare les chercheurs occidentaux de leurs homologues du bloc soviétique ${ }^{60}$. Ksnejia Sergeevna Gorbunova, conservatrice au Musée d'Etat de l'Ermitage, se charge de la rédaction des actualités archéologiques des années 1965 à 1970 dans un exposé concis, mais qui fait désormais une place aux Antiquités scythes et sindes - des peuplades en interaction constante avec la population hellénique du royaume bosporan ${ }^{61}$.

Les deux contributions suivantes sont de la plume de John G. F. Hind, professeur à l'Université de Leeds, également auteur d'une histoire du royaume du Bosphore Cimmérien rédigée pour le compte de la Cambridge Ancient History ${ }^{62}$. Son premier rapport parait dans la livraison de 1983-1984 ${ }^{63}$, le second étant publié une dizaine d'années plus tard, dans la livraison de 1992-1993 ${ }^{64}$. Les deux exposés dénombrent chacun une trentaine de pages - ils témoignent tant de l'excellent degré d'information de leur rédacteur que de l'intensité redoublée de la recherche archéologique en Union Soviétique durant les années 1970 et 1980. De savants tels D. B. Šelov ou I. B. Brašinskij, rapporte Hind, engagent une réflexion globale sur les Etats grecs du bassin de la mer Noire compris comme une entité géographique et économique propre. Les premières études paléo-environnementales, portant notamment sur les fluctuations du niveau de la mer Noire, paraissent à la fin des années 1970. Hind relaie encore dans sa contribution de 1983-1984 l'attention particulière accordée par les Soviétiques à l'étude du parcellaire antique.

59. E. H. Minns, Scythians and Greeks.

6o. "Their work, and that of their Rumanian and Bulgarian colleagues, is still not readely accessible to most western scholars who are as reluctant to learn Eastern languages as the easterners have been to give detailed summaries of their work in any other language", p. 34.

6r. K. S. Gorbunova, «Archaeological Investigations of the Northern Shore of the Black Sea in the Territory of the Soviet Union, 1965-1970».

62. J. G. F. Hind, "The Bosporan Kingdom».

63. J. G. F. Hind, "Greek and Barbarian Peoples on the Shores of the Black Sea».

64. J. G. F. Hind, "Archaeology of the Greeks and Barbarian Peoples around the Black Sea (1982-1992)». 
La parution de la seconde contribution de J. G. F. Hind correspond à la dissolution de l'Union soviétique intervenue officiellement en décembre 1991. Dans son introduction, le rapporteur dépeint avec une certaine appréhension les événements qui aboutirent à la dislocation du bloc socialiste et laissèrent éclater nombre de conflits régionaux au grand jour.

La contribution rédigée par M. J. Treister et J. G. Vinogradov pour le compte de l'American Journal of Archaeology reprend la structure de la synthèse écrite par Šelov en 1980 sur les cités antiques du Pont septentrional et complète en la parfaisant la dernière relation de Hind parue dans les Archaeological Reports ${ }^{65}$. Une première partie fait le bilan des dernières publications ayant marqué la décennie 1980, tandis que la seconde partie est dédiée aux sites archéologiques, présentés ici avec une attention particulière portée aux inscriptions ${ }^{66}$. Les auteurs exposent les problématiques fréquemment abordées par les chercheurs soviétiques; ils évoquent ensuite des essais de typologies archéologiques mises en place par leurs collègues. Les sites de Gorgippia, Phanagorie, Panticapée, Kerkinitis, la chôra de Chersonèse, Bérézan et Olbia jouissent d'un éclairage particulier.

Le dernier rapport archéologique paru à l'enseigne des Archaeological Reports date de 2008; il est le fruit d'une collaboration internationale regroupant des savants issus du Danemark ainsi que de plusieurs pays du bassin de la mer Noire, placés sous la responsabilité éditoriale de Pia Guldager Bilde ${ }^{67}$. La contribution, forte d'une soixantaine de pages dont une quinzaine consacrée aux renvois bibliographiques, parcourt l'entier des côtes du Pont-Euxin. Les auteurs notent une intensification dans l'organisation de colloques et de collaborations internationales ainsi qu'un accroissement des travaux d'édition. Olbia et la partie occidentale de la Crimée bénéficient d'un traitement particulier où l'on perçoit les inclinations personnelles des auteurs. Taures, Sarmates et Scythes «tardifs» profitent de nouveaux élans scientifiques alors que le royaume du Bosphore Cimmérien est traité avec plus de parcimonie.

65. M. J. Treister, Y. G. Vinogradov, "Archaeology on the Northern Coast of the Black Sea".

66. On citera encore l'article de M. Yu. Treister, «Archaeological news from the Northern Pontic Region", qui partage avec la contribution précédente dessein et structure.

67. P. G. Bilde et al., "Archaeology in the Black Sea Region in Classical Antiquity 1993-2007». 
c) Récentes synthèses

Les publications évoquées ci-dessous témoignent du regain d'intérêt que connaissent les établissements grecs du bassin de la mer Noire antique, et son littoral septentrional en particulier. Destinés à un public occidental qui n’aurait pas accès à la littérature originale, ces ouvrages constituent avant tout des compilations de données archéologiques récoltées durant de longues années de fouilles et présentées par des chercheurs reconnus. Ils traitent des établissements grecs qui s'égrenaient à intervalle régulier sur les rives du bassin pontique de manière individuelle et sans prétendre à dresser une synthèse historique ou archéologique valable pour l'ensemble de la région. Outre ces ouvrages, quelques revues occidentales spécialisées ont pour vocation de servir de plateforme aux chercheurs intéressés à cette aire géographique en publiant leurs contributions sur le sujet en traduction ${ }^{68}$.

Jochen Fornasier, Burkhard Böttger (Hrsg.), Das Bosporanische Reich, Mainz, 2002.

L'ouvrage édité en 2002 par J. Fornasier et B. Böttger offre à un public germanophone l'opportunité d'une première familiarisation avec les résultats récents de la recherche archéologique depuis la somme publiée à Berlin par Gajdukevič sur le royaume du Bosphore Cimmérien. Se pliant aux contraintes éditoriales de la série des Bildbände zur Archäologie paraissant à l'enseigne de P. von Zabern, ce volume offre un bilan des fouilles archéologiques menées en Russie de concert avec des universitaires allemands ${ }^{69}$ et illustre le renforcement des liens de collaboration scientifique établis notamment depuis la création, au sein du Deutsches Archäologisches Institut, d'un département d'Eurasie. La contribution des éditeurs, dédiée à l'historique de la recherche, nous paraît bienvenue: elle est très éclairante des conditions auxquelles l'archéologie et, en particulier, les archéologues russes, puis soviétiques, eurent à s'accommoder, s'affranchissant ici de difficultés de terrain, là d'un corset idéologique. Bien qu'elles fassent relativement peu de place au traitement des

68. On mentionnera à titre d'exemple Ancient West \& East, Il Mare Nero ou Ancient Civilizations from Scythia to Siberia.

69. Ainsi en est-il des fouilles de Taganrog, Tanaïs et Vyšesteblievskaja. 
interactions entre Grecs et Barbares ${ }^{70}$, les contributions remplissent le but qui leur était assigné en renseignant un large public des dernières avancées de l'exploration de terrain et en fournissant une importante couverture photographique des éléments exposés. En ce sens, l'ouvrage publié à Mayence a toute son utilité et sert dorénavant de point de départ à toute recherche afférant à ce royaume des marges de l'oikouménè.

D. V. Grammenos, E. K. Petropoulos (eds), Ancient Greek Colonies in the Black Sea, Thessaloniki, 2003, 2 vols (1431 pages).

Dans sa brève introduction aux deux volumes, D. V. Grammenos énonce les buts généraux que se sont fixés les éditeurs de ce projet aux allures encyclopédiques, soit présenter sous la forme d'un recueil les découvertes archéologiques réalisées sur les sites d'une quarantaine de colonies grecques fondées sur tout le pourtour du bassin pontique et offrir ainsi au public occidental l'opportunité de se familiariser avec les investigations d'archéologues dont les recherches sont, la plupart du temps, réputées peu ou pas accessibles.

Les contributions rassemblées par E. K. Petropoulos, docteur de l'Université Lomonossov de Moscou, sont de la plume de spécialistes avérés, en charge de la fouille de sites qu'ils pratiquent depuis de nombreuses années. Les informations fournies sont donc de première main - un atout indiscutable de cette édition en deux forts volumes ${ }^{71}$.

Les éloges que mériterait pareille entreprise sont toutefois sérieusement entamés par des insuffisances manifestes intervenant tant au niveau rédactionnel qu'éditorial. $\mathrm{B}$. Baebler s'indigne de la qualité très variable des traductions, confiées sans doute à des profanes, ce qui nuit non seulement à l'intelligibilité de certains articles, mais porte également préjudice

70. Dans sa recension rédigée pour Sehepunkte, F. S. Knauss dit sa frustration de ne voir traitée la problématique des populations indigènes qu'accessoirement à la présence hellénique dans cette région.

7I. Vol. 1: Apollonia Pontica - Mesambria-Odessos-Histria - Olbia, Bérézan Chôra d'Olbia - Kerkinitis - Chersonèse - Théodosie; Vol. 2: Panticapée - Nymphée - Myrmèkion, Porthmion - Kytée - Kèpoi, Phanagorie, Taganrog - Gorgippia Hermonassa - Tanaïs - Patraeus, Cimmeris, Achilleion - Chôra bosporane - Dioscurias - Gyenos - Phasis - Amisos - Sinope - Heracleia Pontica-Amastris. 
à la visée première de l'œuvre ${ }^{72}$. L'article introductif de E. Petropoulos manque hélas son but et, loin de se poser en prémices méthodologiques à la matière présentée, rend patente l'absence d'un suivi éditorial, qui laisse à la critique un sentiment ambivalent. On rendra cependant grâce aux éditeurs de s'être risqués à publier un panorama représentatif des colonies grecques dans le but de permettre de nouvelles discussions avec les spécialistes de l'Ouest.

D. V. Grammenos, E. K. Petropoulos (eds), Ancient Greek Colonies in the Black Sea 2, Oxford, 2007, 2 vols (1262 pages).

Cette nouvelle livraison ne le cède en rien à la précédente par la somme impressionnante d'informations qu'elle contient. Elle complète la parution de 2003 en présentant d'autres sites archéologiques, omis précédemment, du pourtour pontique de la Bulgarie à la Turquie ${ }^{73}$. Les villes de Tyras ou Trapézonte, par exemple, trouvent place dans cet ouvrage, quand bien même, comme le souligne à raison V. Kozlovskaya, les cités des côtes septentrionales de la Turquie demeurent les parents pauvres de la recherche archéologique ${ }^{74}$. Une série d'essais aux sujets variés - onomastique, numismatique, céramologie, etc. - étoffe encore la présentation des sites archéologiques sans quaucun lien thématique ne les unisse. Aussi, bien que l'effort consenti de rassembler un matériel gigantesque auprès d'une pléiade de spécialistes de plusieurs pays aux traditions d'érudition différentes soit salué, les critiques formulées à l'endroit de cette entreprise grandiose demeurent aiguës. Tant Gocha $\mathrm{R}$. Tsetskhladze que son collègue américain Stanley Burstein relèvent

72. B. Baebler, «D. V. Grammenos, E. K. Petropoulos, Ancient Greek Colonies in the Black Sea».

73. Nous nous contentons de citer les sites archéologiques présentés dans l'orthographe adoptée par l'éditeur, pour le volume 1: Dionysopolis - Bizone - Durankulak Kallatis - Tomis - Tyras - Nikonion - Achilles on the island of Leuke - Olbia Pontica; pour le volume 2: Distant Chora of Taurian Chersonesus and the City of Kalos Limen - Tyritake - Small and poorly studied towns of the ancient Kimmerian Bosporos Iluraton - Torikos - Akra and its chora - Kimmerikon - Ancient greek settlements in Eastern Thrace - Cotyora, Kerasus and Trapezus: The three colonies of Sinope.

74. Cf. V. Kozlovskaya, "Dimitrios V. Grammenos, Elias K. Petropoulos (eds), Ancient Greek Colonies in the Black Sea 2». 
l'absence cruelle de structure de l'édition, l'inexistence d'une ligne éditoriale, qui font des volumes publiés des miscellanées ${ }^{75}$.

Notre tour d'horizon des publications consacrées à l'archéologie et à l'histoire antique du littoral nord de la mer Noire trouve son épilogue naturel dans le champ éditorial francophone, car on peut évoquer à juste titre l'intérêt précoce de savants français pour les antiquités de ce qui était alors le sud de l'Empire russe. Pionnier en ces terres, Désiré RaoulRochette (1789-1854) s'entiche assez de cette contrée pour en brosser l'âge classique, dans un ouvrage paru en 1822 à Paris $^{76}$. Le XIX ${ }^{\mathrm{e}}$ siècle ne s'achèvera pas sans que paraisse une autre synthèse des découvertes archéologiques récentes réalisées en Russie méridionale, sous la plume de Salomon Reinach. Adaptées de la somme publiée par F. Gille, les Antiquités du Bosphore Cimmérien de Reinach sortent de presse en $1892^{77}$.

Les antiquités de Russie méridionale, devenue entretemps soviétique, trouveront un nouvel adepte en la personne de Pierre Lévêque (19212004). L'infatigable historien de l'Antiquité, fondateur à l'Université de Besançon d'une nouvelle approche - décomplexée de tout a priori idéologique - de la matière historique, s'engagea dans l'étude de l'esclavage comme phénomène social au sein des sociétés antiques. Savant multiforme, "décalé», comme le soulignait Pierre Brûlé dans son hommage $^{78}$, Pierre Lévêque sustenta sa curiosité vagabonde par l'exploration du bassin de la mer Noire - ouvrant maintes fois les colonnes de la revue Dialogues d'histoire ancienne aux savants soviétiques -, et sa curiosité analytique par son intérêt pour le marxisme comme outil de lecture des faits historiques. Le cercle des antiquisants soviétiques, puis russes, rendirent à l'éditeur du "Pont-Euxin vu par les Grecs» un hommage appuyé: l'ouvrage de Pierre Lévêque paru en 1969 à Paris, Le monde

75. G. R. Tsetskhladze, «Grammenos (D. V.), Petropoulos (E. K.) (eds), Ancient Greek Colonies in the Black Sea 2", et S. Burstein, "Dimitrios V. Grammenos, Elias K. Petropoulos (eds), Ancient Greek Colonies in the Black Sea 2». J. Morin, "The Greek Expansion to the Black Sea» est plus modéré dans son appréciation.

76. Les fameuses "Antiquités grecques du Bosphore-Cimmérien».

77. S. Reinach, Antiquités du Bosphore Cimmérien.

78. P. Brûlé, «Hommage à Pierre Lévêque». 
hellénistique, fut traduit en russe durant la Perestroïka et augmenté d'une postface de la main de G. A. Košelenko ${ }^{79}$.

Il revient à l'initiative d'Yvon Garlan, un des promoteurs de l'étude du timbre amphorique en France, d'avoir patiemment récolté les articles d'archéologues et d'historiens issus de l'ancienne Union soviétique pour le compte des Dossiers d'archéologie ${ }^{80}$. Les meilleurs spécialistes contribuèrent à cette publication richement illustrée et traduite avec soin à l'attention d'un large public ${ }^{81}$. Košelenko ouvre la série d'études par une présentation où il évoque les spécificités de la colonisation grecque sur le littoral septentrional de la mer Noire et la conquête russe des nouveaux rivages de l'Empire. Dans le lointain sillage d'Hérodote, le lecteur découvrira Olbia, Chersonèse, Panticapée et le royaume du Bosphore Cimmérien, sa partie asiatique et ses kourganes - symboles d'une mixité culturelle à la marge du monde habité.

Les investigations scientifiques franco-russes entreprises sur la presqu'île de Taman en 1997 sont l'occasion d'une communication de Christel Müller publiée dans le Bulletin de Correspondance Hellénique. Il y est fait rapport d'une campagne d'exploration conjointe à l'Ecole française d'Athènes et à l'Institut d'archéologie de Moscou visant à reconstituer l'environnement ancien et actuel de la presqu'île par l'utilisation d'une technologie moderne et adaptée à cette région. Ces travaux permettent de préciser le relief littoral de l'endroit: jusqu'à l'Antiquité tardive, la presqu'île se détachait des pieds du Caucase en une grande île augmentée de trois ou quatre îlots ${ }^{82}$. Dans la livraison de l'année 2000 du même Bulletin, Christel Müller affiche désormais l'ambition de fournir une chronique régulière des sites fouillés du Bosphore Cimmérien, qu'elle réalisera durant les années suivantes, en suivant l'ordre géographique de présentation des sites archéologiques adopté plus

79. Cette postface présente un intérêt historiographique particulier: à la veille de la chute de l'URSS, Košelenko s'ingénue à justifier la terminologie employée par P. Lévêque, plus précisément, à en redresser les écarts en regard de la doctrine soviétique.

80. AA.VV., Entre Scythes et Grecs.

8I. Ce beau panorama est servi notamment par les plumes éprouvées de V. D. Kouznetsov, S. D. Kryjitskij, V. M. Zoubar, V. P. Tolstikov, E. M. Alekseeva, E. A. Savostina, A. A. Maslennikov ou T. M. Arsenieva, qui figurent parmi les meilleurs spécialistes soviétiques de cette époque.

82. Ch. Müller et al., "Péninsule de Taman». 
tôt par G. A. Košelenko dans la publication qu'il dirigeait en $1984^{83}$. Ce pari audacieux arrime à nouveau la recherche archéologique française contemporaine à une tradition dont elle s'était éloignée. La systématique engagée et le concours acquis des responsables russes et ukrainiens en charge des fouilles assurent un accès sérieux et documenté au lecteur francophone intéressé par le royaume du Bosphore Cimmérien, par Olbia et Chersonèse ${ }^{84}$. Les chroniques de 2002 et 2004 sont bien documentées et offrent un aperçu de choix des derniers travaux en recherche archéologique menée dans le Bosphore Cimmérien ${ }^{85}$. Certainement très précieuse à un public ignorant du russe, la chronique tenue par Ch. Müller manque toutefois de réintégrer les problématiques agitées par ses collègues de l'ex-URSS au contexte dont elles sont issues, à cet héritage prérévolutionnaire et, ensuite bien sûr, soviétique. Par souci de clarté, nous semble-t-il, ce champ d'études extraordinaire (pour qui ose s'y introduire) demande à être appréhendé avec son contexte historique sous peine d'apparaître tronqué voire nivelé et déprécié de ses spécificités.

\section{Conclusion}

De ce bref parcours à travers l'histoire de l'archéologie des Etats grecs fondés sur le littoral septentrional de la mer Noire, du royaume du Bosphore Cimmérien en particulier, nous pouvons tirer quelques conclusions générales aptes à ouvrir de nouvelles perspectives de recherche. Loin d'être anecdotique, le retour amorcé aux écrits de nos prédécesseurs $\mathrm{du} \mathrm{XIX}^{\mathrm{e}}$ siècle est riche d'enseignements multiples dont le moindre n'est pas, pour un archéologue, le témoignage du voyageur curieux faisant

83. Ch. Müller utilise, comme point de départ de ses comptes rendus bibliographiques, la publication dirigée par Košelenko (cf. la recension rédigée par A. Wąsowicz, "Une nouvelle Archéologie de l'URSS»).

84. La livraison de l'an 2000 (Ch. Müller, «Chroniques des fouilles et découvertes archéologiques dans le Bosphore cimmérien") passe successivement en revue les sites de Panticapée, Nymphaion, Myrmèkion, la chôra du Bosphore - Cap Kazantip Phanagorie - Gorgippia - Képoi - Patrasys - Ilitch - Jubilejnoe - Blagovechenskoe, enfin la région de Novorossijsk.

85. Ch. Müller "Chroniques des fouilles et découvertes archéologiques dans le Bosphore cimmérien (mer Noire septentrionale) II" et "Chroniques des fouilles et découvertes archéologiques dans le Bosphore cimmérien (mer Noire septentrionale) III». 
rapport détaillé de sites archéologiques aujourd'hui dégradés par l'activité humaine ou abîmés par les éléments naturels. Ce travail de redécouverte d'un héritage d'érudition n'en est encore qu'à ses débuts, tant en Russie que dans le monde occidental. Car l'intérêt porté à cette volumineuse documentation dépasse de beaucoup de pures préoccupations archivistiques. Malgré tous les débats qu'il a vu naître en Russie, sur l'appartenance culturelle, politique ou religieuse du pays à l'Europe ou à l'Asie par exemple, le XIX ${ }^{\mathrm{e}}$ siècle représente un segment commun de l'histoire et des valeurs que prétendent partager les grandes puissances européennes, de l'entrée d'Alexandre I ${ }^{\text {er }}$ à Paris en vainqueur de Napoléon à la venue de Félix Faure à Saint-Pétersbourg, en allié de la Russie impériale.

La période qui suit la chute du tsarisme n'en est pas moins intéressante. Bientôt engoncée dans un corset idéologique étroit, l'archéologie - et les sciences de l'Antiquité en général - se soumet à une redéfinition de ses tâches. C'est ainsi que l'archéologue soviétique des établissements grecs de la mer Noire obéit à de nouvelles prescriptions dictées par des principes doctrinaires. L'indispensable distance critique maintenant acquise, depuis la chute de l'URSS et l'avènement, en Russie même, d'une génération libre de la propagande soviétique, une nouvelle approche de l'archéologie telle qu'elle était exercée en URSS doit poindre; plus ouverte à mesure qu'elle se sera affranchie d'a priori idéologiques, elle parviendra à dresser le portrait sincère d'une discipline, à en dégager les fondements, à en établir les évolutions et à en apprécier la portée épistémologique.

Enfin, les publications récentes compilant des données essentielles à la connaissance même de sites archéologiques du Pont-Euxin et à leur intégration dans l'oikouménè méditerranéenne doivent stimuler les démarches scientifiques visant à la confrontation des données et à leur systématisation progressive. Parallèlement, nous semble-t-il, l'héritage des problématiques traitées durant l'URSS, encore mal assumé, mérite d'être réinvesti et recontextualisé pour une meilleure appréciation des traits originaux et des apports réels de l'archéologie soviétique.

Pascal Burgunder

Institut d'Archéologie et des Sciences de l'Antiquité

Université de Lausanne 


\section{BIBLIOGRAPHIE}

AA.VV., Entre Scythes et Grecs, Dossiers d'archéologie, 188 (1993).

Baebler, Balbina, "D. V. Grammenos, E. K. Petropoulos, Ancient Greek Colonies in the Black Sea", Bryn Mawr Classical Review, 2004.09.01.

Bilde, Pia Guldager et al., "Archaeology in the Black Sea Region in Classical Antiquity 1993-2007", Archaeological Reports, 54 (20072008), p. 115-173.

Boardman, John, "Greek Archaeology Investigations of the Shores of the Black Sea", Archaeological Reports, 9 (1962-1963), p. 33-51.

Boltounova, Anna, "L'épigraphique (sic) en URSS", Klio, 51 (1969), p. 299-308.

Boltunova, Anna Ivanovna, "Neskol'ko slov o "Korpuse Bosporskikh nadpisej" " " Quelques mots à propos du Corpus des inscriptions bosporanes»], Vestnik Drevnej Istorii, 4 (1966), p. 230-233.

Boltunova, Anna Ivanovna, Knipovič, Tat’ jana Nikolaevna, "Očerk istorii grečeskogo lapidarnogo pis'ma na Bospore» ["Essai d'histoire du caractère lapidaire grec dans le Bosphore»], Numizmatika i Ėpigrafika, III (1962), p. 3-31.

Bosi, Fausto, "Note epigrafiche bosporane», Epigraphika, 29 (1967), p. 131-144.

BRÛlÉ, Pierre, "Hommage à Pierre Lévêque", Kernos, 18 (2005), p. 11-15. Burgunder, Pascal, Semenzato, Camille "Retour à Alexandrie?", AA.VV., Actes du colloque Ductus (Lausanne 2008), à paraître.

Burstein, Stanley, "Dimitrios V. Grammenos, Elias K. Petropoulos (eds), Ancient Greek Colonies in the Black Sea 2", Bryn Mawr Classical Review, 2009.06.15.

Buzeskul, Vladislav Petrovič, Vseobščaja istorija i ee predstaviteli $v$ Rossii v XIX i načale XX veka [L'histoire universelle et ses représentants en Russie au XIX $X^{e}$ siècle et au début du XX $X^{e}$ siècle], sost. Irina Vladimirovna Tunkina, Moskva, Indrik, 2008 (2 éd.). 
Dubois de Montperreux, Frédéric, Voyage au Caucase, chez les Tcherkesses et les Abkhases, en Colchide, en Géorgie, en Arménie et en Crimée, 6 vols, Paris, Librairie de Gide, 1839-1843.

Fornasier, Jochen, Böttger, Burkhard (Hrsg.), Das Bosporanische Reich, Mainz, von Zabern, 2002.

Frolov, Ėduard Davydovič, "Kavaler ordena belogo orla: Vasilij Vasil'evič Latyšev - učjonij-klassik, pedagog i obščestvennij dejatel' staroj Rossii (1855-1921)" ["Chevalier de l'ordre de l'Aigle blanc: Vasilij Vasil'evič Latyšev - le savant-antiquisant, le pédagogue et l'homme public de la Russie ancienne (1855-1921)»], in V. V. Latyšev, Očerk grečeskikh drevnostej [Essai sur les antiquités grecques], Sankt-Peterburg, Aletejja, 1997, vol. I, p. I-XXXI (réédition de la troisième édition parue en 1897).

—, Russkaja nauka ob antičnosti [La science russe et l'Antiquité], SankPeterburg, Izdatel'stvo SPbGU, 1999.

Gajdukevič, V[iktor] F[rancevič], Das Bosporanische Reich, Berlin/ Amsterdam, Akademie Verlag, 1971.

Gauthier, Philippe, "A propos de l'ouvrage de Jurij G. Vinogradov, Pontische Studien", CRAI, (1998), col. 1185-1188.

Gavrilov, Aleksandr Konstantinovič, " $\mathrm{K}$ istorii $K B N$ i ego fotoarkhiva» "A propos de l'histoire du CIRB et de ses archives photographiques»], in Corpus Inscriptionum Regni Bosporani: Album Imaginum, ed. Aleksandr Konstantinovič Gavrilov et al., Petropoli, Bibliotheca Classica Petropolitana, 2004, p. 395-413.

Gavrilov, Aleksandr Konstantinovič et al. (ed.), Corpus Inscriptionum Regni Bosporani: Album Imaginum, Petropoli, Bibliotheca Classica Petropolitana, 2004.

Gille, Florian, Antiquités du Bosphore Cimmérien conservées au Musée impérial de l'Ermitage, 2 vols, Saint-Pétersbourg, 1854.

—, Musée de l'Ermitage: notice sur la formation de ce musée et description des collections diverses, Saint-Pétersbourg, 1860.

Gorbunova, Ksenija Sergeevna, "Archaeological Investigations of the Northern Shore of the Black Sea in the Territory of the Soviet Union, 1965-1970", Archaeological Reports, 18 (1971-1972), p. 48-59.

Grammenos, Dimitrios V., Petropoulos, Elias K. (eds), Ancient Greek Colonies in the Black Sea, 2 vols, Thessaloniki, 2003.

-, Ancient Greek Colonies in the Black Sea 2, 2 vols, Oxford, 2007. 
Heinen, Heinz (dir.), Die Geschichte des Altertums im Spiegel der sowjetischen Forschung, Darmstadt, Wissenschaftliche Buchgesellschaft, 1980.

Hind, John G. F., "Greek and Barbarian Peoples on the Shores of the Black Sea", Archaeological Reports, 30 (1983-1984), p. 71-97.

—, "Archaeology of the Greeks and Barbarian Peoples around the Black Sea (1982-1992)", Archaeological Reports, 39 (1992-1993), p. 82-112.

—, "The Bosporan Kingdom», Cambridge ancient history $\mathrm{VI}^{2}$ : The fourth century B.C., Cambridge, Cambridge University Press, 1994, p. 476-511.

—, "J. G. Vinogradov, Pontische Studien", Journal of Hellenic Studies, 124 (2004), p. 195-196.

Jajlenko, Valerij Petrovič, «Ju. G. Vinogradov. Pontische Studien. Kleine Schriften zur Geschichte und Epigraphik des Schwarzmeerraumes", Rossijskaja Arkheologija, 3 (2000), p. 181-192.

—, "Ueber den Umgang mit pontischen Inschriften ", Das Altertum, 4 (2001), p. 223-232 (traduction allemande de la recension précédente).

King, Charles, The Black Sea. A history, Oxford, Oxford University Press, 2004.

Knauss, Florian S., "Jochen Fornasier, Burkhard Böttger (Hrsg.), Das Bosporanische Reich», Sehepunkte, 4 (2004), Nr. 11 voir www. sehepunkte.de/2004/11/4878.html (consulté le 28.02.2012).

Knoepfler, Denis, “Misit Dubois Neoburgensis”. La contribution du Neuchâtelois Frédéric Dubois de Montperreux à l'épigraphie de la côte septentrionale de la mer Noire", in Actes du VII Congrès international d'épigraphie grecque et latine, éd. par D. M. Pippidi, Bucuresti/Paris, Editura Academiei/Les Belles Lettres, 1979, p. 391-392.

—, "Frédéric Dubois de Montperreux", in AA.VV., Histoire de l'Université de Neuchâtel, Tome I: La première Académie (1838-1848), Neuchâtel/Hauterive, Université de Neuchâtel/G. Attinger, 1988, p. 257-304.

Koromila, Marianna, The Greeks and the Black Sea. From the Bronze Age to the early twentieth century, Athens, The Panorama Cultural Society, 2002. 
Kozlovskaya, Valeriya, "Dimitrios V. Grammenos, Elias K. Petropoulos (eds), Ancient Greek Colonies in the Black Sea 2», Bryn Mawr Classical Review, 2009.04.79.

KrJuger, Otto Oskarovič, «Korpus bosporskikh nadpisej» ["Le Corpus des inscriptions bosporanes»], Vestnik Drevnej Istorii, 2 (1966), p. 176-183.

Latyšev, Vasilij Vasil'evič, Inscriptiones Orae Septentrionalis Ponti Euxeini Graecae et Latinae (IOSPE), 3 vols, Petropoli, 1885-1901.

-, Očerk grečeskikh drevnostej [Essai sur les antiquités grecques], 2 vols, Sankt-Peterburg, Aletejja, 1997 (réédition de la troisième édition parue en 1897).

Minns, Ellis H., Scythians and Greeks: a survey of ancient history and archaeology on the north coast of the Euxine from the Danube to the Caucasus, Cambridge, Cambridge University Press, 1913.

Mongait, A[leksandr] L['vovič], Archaeology in the USSR, London, Penguin Books, 1961.

Morin, Jacques, "The Greek Expansion to the Black Sea", American Journal of Archaeology, 113 (2009), p. 129-133.

Müller, Christel, "Chroniques des fouilles et découvertes archéologiques dans le Bosphore cimmérien (mer Noire septentrionale) II", Bulletin de Correspondance Hellénique, 126.2 (2002), p. 729-750.

—, "Chroniques des fouilles et découvertes archéologiques dans le Bosphore cimmérien (mer Noire septentrionale) III", Bulletin de Correspondance Hellénique, 128-129 2.2 (2004-2005), p. 1709-1745.

Müller, Christel, Fouache, Eric, Gaïbov, Vassif, Gorlov, Youri, "Péninsule de Taman (Russie méridionale)», Bulletin de Correspondance Hellénique, 122.2 (1998), p. 643-654.

MülLER, Christel et al., "Chroniques des fouilles et découvertes archéologiques dans le Bosphore cimmérien (mer Noire septentrionale)", Bulletin de Correspondance Hellénique, 124.2 (2000), p. 701-751.

NADEL, Benjamin, "Le Corpus inscriptionum regni Bosporani et quelques questions de méthode en épigraphie", Meander, XXIII (1968), p. 61-79.

—, "Le royaume du Bosphore, un millénaire de civilisation grecque en pays scythe (à propos d'un ouvrage récent)", Revue historique de droit français et étranger, 53 (1975), p. 258-267. 
—, "V. F. Gaidukevic: Das Bosporanische Reich», Gnomon, XLVII (1975), p. 567-577.

Pavlova, Germaine, "39 Jahre am Hof zweier Zaren. Florian Gille in St. Petersburg und in der Eremitage (1825-1864)», in Von Zürich nach Kamtschatka: Schweizer im Russischen Reich, hrsg. von Eva Maeder, Peter Niederhäuser, Zürich, Kronos Verlag, 2008, p. 54-66.

Pavlova, Žermena Konstantinovna, Florian Žil' i Imperatorskij Ermitaž. Žizn' i sud'ba [Florian Gille et l'Ermitage impérial. Vie et destinée], Sankt-Peterburg, Nestor-Istorija, 2010.

Pecirka, Jan, "Corpus inscriptionum regni Bosporani (C.I.R.B.). Korpus bosporskikh nadpisei. Moscow: Nauka, 1965 ", Journal of Hellenic Studies, 1966, p. 294-296.

Pigulevskaja, Ninna Viktorovna, "Korpus bosporskikh drevnostej", Voprosy Istorii, 1 (1966), p. 180-182.

Raoul-Rochette, Désiré, Antiquités grecques du Bosphore-Cimmérien, Paris, Firmin Didot, 1822.

Reinach, Salomon, Antiquités du Bosphore Cimmérien, Paris, FirminDidot, 1892.

Rostowzew, M[ikhail Ivanovič], Skythien und der Bosporus, Bd. I: Kritische Übersicht der schriftlichen und archäologishen Quellen, Berlin, H. Schoetz, 1931 (erweiterte Fassung der russischen Ausgabe von 1925).

Rubinsohn, Zeev W., "Saumakos: Ancient history, modern politics», Historia, 29 (1980), p. 50-70.

Russu, Ioan I., "Corpus inscriptionum regni bosporani (CIRB)", Studii Classice, VIII (1966), p. 334-339.

Schulz-Falkenthal, Heinz, "V. F. Gajdukevič, Das Bosporanische Reich", Deutsche Literaturzeitung für Kritik der internationalen Wissenschaft, XCII (1971), col. 903-906.

Struve, Vasilij Vasil'evič et al., Korpus bosporskikh nadpisej (CIRB) [Corpus des inscriptions bosporanes], Leningrad/Moskva, Nauka, 1965.

Tokntas'ev, Sergej Remirovič, "Iz onomastiki Severnogo Pričernomor'ja I» ["De l'onomastique du littoral nord de la mer Noire I»], in Problemy antičnogo istočnikovedenija, otv. red. Èduard Davydovič Frolov, Moskva/Leningrad, Leningradskoe Otdelenie Instituta Istorii AN SSSR, 1986, p. 69-87. 
—, «Iz onomastiki Severnogo Pričernomor’ja II. Frakijskie imena na Bospore» " De l'onomastique du littoral nord de la mer Noire II. Noms thraces dans le Bosphore»], in Etjudy po antičnoj istorii i kul'ture Severnogo Pričernomor' ja [Etudes d'histoire antique et de culture du littoral septentrional de la mer Noire], otv. red. Aleksandr Konstantinovič Gavrilov, Sankt-Peterburg, Izdatel'stvo Glagol, 1992, p. 178-199.

Treister, Michail Yu., "Archaeological news from the Northern Pontic Region", Ancient Civilizations from Scythia to Siberia, 1 (1994), p. 2-39.

Treister, Michail J., Vinogradov, Yuri G., "Archaeology on the Northern Coast of the Black Sea", American Journal of Archaeology, 97 (1993), p. 521-563.

Tsetskhladze, Gocha R., "Grammenos (D. V.), Petropoulos (E. K.), (eds) Ancient Greek Colonies in the Black Sea 2", Classical Review, 59.2 (2009), p. 534-536.

Vinogradov, Ju[rij] G[ermanovič], "Epigraphik in der UdSSR", Arheološki Vestnik (Ljubljana), 31 (1980), p. 301-316.

—, Olbia: Geschichte einer altgriechischen Stadt am Schwarzen Meer, Konstanz, Universitätsverlag, 1981.

—, "Bulletin Epigraphique: Côte septentrionale du Pont, Caucase, Asie centrale», Revue des Etudes Grecques, 103 (1990), p. 531-560.

—, "Bulletin Epigraphique: Pont Nord», Revue des Etudes Grecques, 109 (1996), p. 607-612.

—, Pontische Studien. Kleine Schriften zur Geschichte und Epigraphik des Schwarzmeerraumes, Mainz, von Zabern, 1997.

VInogradov, Jurij Alekseevič, "Pamjati V. F. Gajdukeviča” ["A la mémoire de V. F. Gajdukevič»], Bosporskie issledovanija, XIII (2006), p. 3-15.

WĄsowicz, Aleksandra, "Une nouvelle Archéologie de l'URSS", Dialogues d'Histoire Ancienne, 12 (1986), p. 509-516.

Yanine, V[alentin Lavrent'evič] (dir.), Fouilles et recherches archéologiques en URSS, Moscou, Editions du progrès, 1985.

ŽArkov, Evgenij Igorevič (otv. red.), Sotrudniki feodosijskogo muzeja drevnostej - dejateli nauki i kul'tury. Biobibliografičeskij slovar' [Les collaborateurs du Musée des Antiquités de Théodosie - acteurs de la science et de la culture. Dictionnaire biobibliographique], Kiev, Bolero, 2011. 


\section{Crédits iconographiques}

Fig. 1:

Estampe de R. Rahn, graveur J. Notz.

Fig. 2:

Archives du Musée des Antiquités de Théodosie, N inv. Ф-1095.

Fig. 3:

Archives de l'Académie des Sciences de Russie, Saint-Pétersbourg. ПФA РАН, РХ Оп. 1-1, Д.42, нег. 1380. 
